\title{
The Impact of the 2019-nCoV on the Oral Medical Industry and the Corresponding Strategies
}

\author{
Chen Yanbing ${ }^{1}$ \\ ${ }^{1}$ Taxation, School of Finance and Public Administration, Yunnan University of Finance and Economics, Kunming, Yunnan
}

\begin{abstract}
The outbreak of new crown pneumonia has had a great impact on Chinese enterprises. As a highly market-oriented medical vertical segment industry, oral institutions have been impacted and affected unprecedentedly in this epidemic. Through the analysis of the specific impact on the stomatology industry, this paper puts forward and its countermeasures, and provides suggestions for enterprises to eliminate the negative impact of the epidemic on enterprises to the greatest extent and promote the benign development of enterprises.
\end{abstract}

\section{BRIEF INTRODUCTION OF ORAL CAVITY MEDICINE INDUSTRY}

At present, with the rapid development of China's economy and the change of national diet, the incidence rate of oral diseases has been increasing in China and people's awareness of oral health care is also constantly strengthening. Accordingly, the medical technology in the field of stomatology has made continuous progress and the state has increased policy support for the oral cavity medical industry, which has brought rapid and vigorous development to the oral cavity medical industry. China's oral cavity medical market has been in a golden period, which is related to the national economy and people's livelihood. Therefore, the impact of the epidemic on the oral industry is quite obvious.

\subsection{General situation of oral medicine industry}

There are 3 management models in China's oral health care industry. The first is the large and medium-sized non-profit hospitals that dominate the market, which have absolute advantages in the scope of medical insurance, but are limited by the system, with low marketization and slow development. The second is the individual dental clinic, which has a large number at present, and is targeted at the low-end market. The third is brand oral chain, which can not only establish the trust of patients to doctors, but also provide opportunities for the establishment of new brands and even large-scale operation.

\subsection{The characteristics of oral medical industry}

\subsubsection{Consumer groups are wide and the level of circular consumption is high.}

Oral industry has the advantages of repeated consumption and standardization. The four major businesses are aimed at high-end consumers. The four major dental businesses are orthodontics, oral implant, tooth whitening, and children's dentistry, all of which are sustainable consumption items, and some of them have high prices. What's more, they belong to non-medical insurance optional consumption. Dental projects often can't be completed by surgery and other means at one time. Patients need to continue to receive dental treatment within 1-2 years, with a high level of recycling consumption.

\subsubsection{Individual management is the main task, and patients pay attention to convenience.}

Compared with other departments, the safety of oral health care is higher and it is not easy to have disputes between doctors and patients. The fixed assets investment is low, and most dental projects are not within the scope of medical insurance. Dentists in private dental clinics do not need to deal with medical insurance, and patients pay more attention to convenience. Therefore, the management mode of stomatological hospital is mostly individual operation. In the long run, the stomatological hospital not only has good brand image, but also its passenger flow is stable, and the future development space is huge. 


\subsubsection{The operating profit is rich and the industry has a bright future.}

With the increase of per capita treatment cost and the rate of treatment in China, there is still a lot of room for development of oral medical market. The growth opportunities of oral cavity medicine industry have attracted the attention of a large number of capital. The gross profit rate of oral cavity medicine enterprises is very high, which is about $40 \%-60 \%$. The number of oral medical enterprises has been growing steadily since 2011, and reaching the outbreak period in 2015 which 22 related companies were established in 2015. In terms of financing, since 2014, there have been a total of 15 financing activities of more than tens of thousands of US dollars in the stomatology industry, and 5 financing activities of more than US $\$ 5000000$ in 2017 alone. After obtaining the financing, almost all the oral cavity chain hospitals have been on the road of rapid expansion to seize the blank market as soon as possible.

\subsubsection{Doctors are well paid and need a steady client base.}

When hospitals are unable to increase dentists' income and reduce practice costs, dentists are more likely to be in independent practice rather than working within a hospital system. Most dental businesses are non-medical insurance projects, and do not require cross department and large-scale team cooperation. At the same time, the investment threshold of individual dental clinics is low. Therefore, dentists with medical experience, stable customer base and initial capital, can practice independently without being limited by the hospital salary system and get higher remuneration.

\section{IMPACT OF 2019-NOCV ON ORAL CAVITY MEDICINE INDUSTRY}

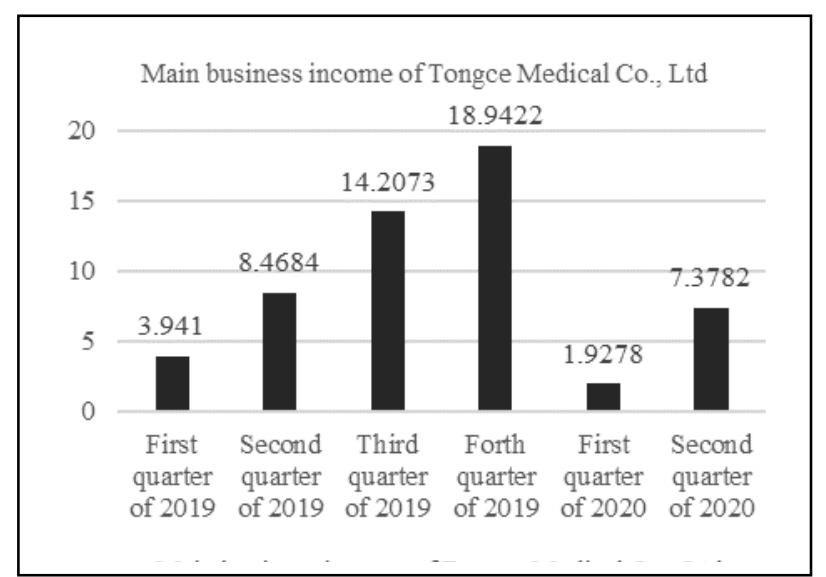

Figure 1. Main business income of Tongce Medical Co., Ltd

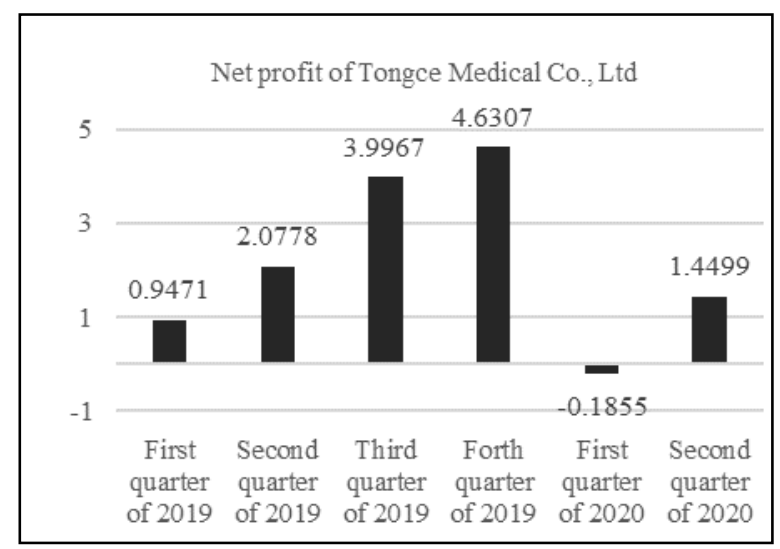

Figure 2. Net profit of Tongce Medical Co., Ltd

Taking Tongce Medical Co., Ltd 's operation from the first quarter of 2019 to the second quarter of 2020 as an example, it can be clearly seen from the figure that its main operating income in the first quarter of 2020 has greatly decreased compared with the previous quarter, and its net profit is negative, which is greatly affected by the epidemic situation.

\subsection{The impact on operating conditions}

In the process of oral treatment, some special equipment such as high-speed turbine handpieces and mouth cleaners will produce a large amount of water mist, droplets or aerosols when they work. If there are patients with a latent period who are not aware of it and carry out oral diagnosis and treatment operation, it will be very easy to lead to the spread of the epidemic. Under the epidemic situation, the oral cavity medicine industry has become a high-risk industry, which also makes the oral cavity medicine industry return to work much harder than other industries. Due to the epidemic, most enterprises have been in a state of unemployment for two months.

In the case of total disruption of offline operations, many enterprises not only open new online markets by opening stores on WeChat platform and e-commerce platforms such as Taobao, Tmall and so on, but also carry out the publicity through employees' forwarding. What's more, they offer some special cash coupons and packages to attract consumers, aiming at grabbing customers who have relevant needs but cannot go out for medical treatment.

In terms of efficiency, the online market of many enterprises is successful, which brings certain benefits to the enterprises. It can be attributed to two modules: one is that patients with different types and different degrees of oral diseases have no place to treat due to the epidemic, so they can realize the online consultation and offline appointment of professional doctors with online coupons; the other is with the help of marketing strategies, setting up staff-centered group chat with professionals in the group to answer questions which creates an atmosphere and then completes some orders.

Many companies said that this new business model has a positive inspiration for the future development of the company. Compared to the previous offline operation, 
companies now have online business channels which have more advantages, such as broader coverage, lower sales promotion costs, longer effect duration, more flexible changes and so on. Many companies make it clear that they will operate and continually improve the online marketplace thereafter.

\subsection{The impact on the financial situation.}

During the epidemc, while unable to operate, companies were faced with the necessary expenses, the largest of which came from shop rent and staff wages. Although some businesses take advantage of the $50 \%$ discount on store rent, the portion that needs to be paid is still a big burden for companies that are not in business. What's more, the raw materials required by the company, such as masks, protective clothing and so on, have a certain overlap with the medical materials required during the epidemic, resulting in large price increases and few purchasing channels.

In terms of revenue, although enterprises have set up online markets, they generally charge lower prices in order to promote sales and stabilize customers. Therefore, enterprises are in the stage of high expenditure and low income.

\subsection{The impact on the situation of stuff}

During the epidemic, many companies pay their salaries normally and also actively organize some training. The aim is to take advantage of this free period to improve the professional skills and overall quality of employees. Many enterprises have low demand for labor due to a significant reduction in demand and also to save money. However, some enterprises indicated that with the relaxation of traffic control and the full recovery of their business, there will be no significant fluctuation in the number of staff required.

\subsection{The impact on market demand}

The epidemic will affect people in many ways, from the attitude of people treating minor illness to people's outlook on life and value. In terms of general trends, people will be more reverence of life and more concerned about their health. Although the market demand is in the doldrums, enterprises are generally optimistic about the growth of demand after the epidemic.

\section{RESPONSE STRATEGIES OF ENTERPRISES}

\subsection{Know more abhout the preferential policies of the government.}

The central and local governments have successively introduced policies and measures to help enterprises tide over the difficult times, including tax reduction and exemption, extension of tax declaration, low interest discount loan, financing guarantee, extended repayment or renewal of loan, bond issuance support, extension of employee insurance, refund of trade union funds and enterprise dues, reduction or postponement of rent and water and electricity charges, phased reduction or waivers of corporate social security, deferment of corporate provident fund payments and so on. The oral cavity medicine industry is among the last industries to resume work, and the rent and employee salary are the main capital expenditure borne by the enterprise. In the case of a significant decrease in operating income, the company can only basically maintain a state of balance between revenue and expenditure. Although most enterprises enjoyed the preferential policy of halving the rent, did not know much about other policies.

\subsection{Strengthen staff management and training.}

Enterprises use this opportunity to strengthen the management and training of doctors and nurses, and arrange online master lectures and oral surgery videos to improve the professionalism of doctors and nurses. Daily clocking and learning are linked to employee performance. Because of the high risk of infection in the oral industry after the outbreak of the epidemic, the national secondary protection training was conducted for each employee on duty under the requirements of the Health Bureau. During the operation period of the enterprise, the number of customers affected by the epidemic situation has been greatly reduced. The enterprise and its employees have reached a consensus through consultation to stabilize their jobs by adjusting their salaries, taking turns to work, shortening working hours and waiting for jobs.

\subsection{Develop the online markets.}

The daily marketing mode of enterprises is mainly through offline oral knowledge propaganda and free oral health examination activities. However, due to the 2019$\mathrm{nCoV}$, the traditional marketing methods of the oral industry have been hindered. In order to seize the market and obtain new customer orders, enterprise has opened an online micro store, where special preferential cash coupons and some packages, such as children's package, orthodontic package, planting package and so on, are put on the micro shop. If patients have any oral problems during the epidemic, they can purchase packages online in the form of professional consultation with dentists.

\section{RECOMMENDATIONS FOR ENTERPRISES AFFECTED BY THE EPIDEMIC SITUATION}

\subsection{Finance from multiple channels to ensure the smooth operation of enterprises.}

Most oral health facilities are independently owned and privately owned, small in size, and generally fall under the category of micro, small and medium enterprises. Most of them have low risk resistance and are characterized by vulnerability. What's worse, the 
outbreak and continuation of the epidemic have increased their vulnerability. Whether it is the cost of the duration of the epidemic, or the production, operation and procurement after the resumption of work, it is necessary to maintain funds.

In order to cope with the above-mentioned capital problems, enterprises need to mobilize various forces to ensure capital flow and raise funds most urgently. For example, we should make good use of relevant government support policies and funds. What's more, we can also communicate with employees to reduce labor costs through salary reduction, performance reduction and salary deferral. If necessary, we should strictly control office expenses, travel expenses, marketing and promotion expenses by reducing business, especially eliminating unnecessary markets and projects. Actively communicating with property owners and strive to reduce part of advertising rental is also a good way. In addition, more flexible and diversified financing methods should be adopted, including deposit and deposit transfer order, financial and tax outsourcing, collaborative office and so on.

\subsection{Develop the market actively and make up for the loss of orders during the shutdown period.}

After the epidemic has been controlled to a certain extent, enterprises should actively carry out market development and look for orders to make up for the operating income lost during the shutdown period. Enterprises should not only expand the market relying on the policy, but also actively innovate the marketing model and carry out full marketing. When enterprises explore new markets and new customers, they should find ways to maintain existing customers at the same time. For the delay in delivery caused by the epidemic, enterprises should communicate with customers in a timely manner, strive for the understanding of customers, and give customers certain preferential treatment in the price, service or other terms. In addition, marketing promotion can be carried out through new media and other means to make full use of the advantages of online marketing.

\subsection{Accelerate the transformation of enterprises and develop new business models.}

After the end of the SARS in 2003, Internet companies emerged, releasing huge business opportunities. Likewise, the new coronary pneumonia epidemic will give birth to and promote new businesses such as the digital economy, medical wellness, and ecological protection. In the prevention and control of the epidemic, many enterprises have made great use of digital means, such as data submission, notification and communication, event communication, material distribution, personnel management, network office, remote meeting, online education, remote medical treatment, policy release, online consumption and so on. The digital economy highlights its unique advantages. Enterprises should seriously learn the lessons brought about by this 2019$\mathrm{nCoV}$, and actively promote transformation of the enterprise, upgrade to high value-added industrial chain and transform to digital economy industry. Enterprises should accelerate the development of new business models and carry out diversified sales channel transformation. What's more, enterprises can give full play to the role of Alibaba, Jing Dong, Amazon, Netease and other Internet platform enterprises to expand online sales. The added value of marketing channels can be improved by moderately embedding cloud technology and blockchain technology through Mini Program, Group chats and other means.

\subsection{Expand the supply chain to realize multi- channel procurement of materials.}

After the resumption of production, most of the enterprises are facing problems such as product shortage, shortage, upstream supply difficulties and so on. The core work of enterprises after resumption of production is to pay attention to the supply chain, communicate with upstream suppliers and downstream channel providers in a timely manner, judge the supply capacity and order demand of enterprises after resumption of production, maintain supply chain resources by customer relationship, actively make alternative plans and multi-channel procurement, and consider cross-border procurement when necessary.

In addition to strengthening the contact with suppliers, enterprises should also pay close attention to their dynamics, such as resumption time, statistics of employees, upstream raw materials, order status, capital chain issues and so on. Enterprises may consider prepayment or deposit to ensure the priority of supply from upstream suppliers according to the situation, and cooperate with the enterprise which has a weak supply chain, so as to complement each other's disadvantages and strengthen their advantages. By providing necessary funds and disinfection materials for upstream highquality or core suppliers, enterprises will strive to obtain the opportunity of priority procurement of raw materials urgently needed after resumption of work, and effectively enhance customer relationship, so as to build a solid foundation for subsequent construction.

\subsection{Pay attention to the psychological and emotional problems of employees, and gradually resume work and life.}

When the epidemic situation of the 2019-nCoV is relatively serious, not only the owners but also employees of the enterprise have different levels of fear, and their spiritual level will be affected by the impact and impact of the epidemic. In order to effectively reduce the negative impact caused by the epidemic and Internet public opinion, business owners and employees should actively spread positive energy and deal with the epidemic rationally. After doing prevention and control seriously, enterprises should have the courage to resume normal work and life. Enterprises can appropriately strengthen mental health management and support for employees, and give appropriate material and spiritual 
support to employees and families affected by the epidemic to minimize the negative emotions brought about by the epidemic.

\section{Conclusion}

The 2019-nCoV did cause a relatively heavy hit to the oral health industry in general, but enterprises should carry out correct financing to ensure the operation and resumption of production, consolidate the supply chain to open up the supply chain after resumption of production, increase market development to make up for the loss of the suspension period, actively promote enterprise transformation to improve industrial added value, make use of policy dividends to and effectively reduce the loss of the epidemic, pay attention to psychological and emotional issues to ensure the mental health of the owners and employees of the enterprise, to eliminate the negative impact of the epidemic on the enterprise to the greatest extent, and promote the benign development of the enterprise.

\section{REFERENCES}

1. Feng Jianqiao, Yi Xiaofeng. The Epidemic Situation Brings New Ideas to the Development of Stomatology [n]. Health news, April 21, 2020 (008).

2. Wang Tao. Dental medical industry has been severely damaged. Why can Rongdai oral medicine cope with it calmly? [J]. Chinese foreign management, 2020 (04): 126-128.

3. Shen Shuming. Problems and Thinking of Stomatological Institutions in Response to National Public Health Emergencies [J / OL]. Chinese Journal of Stomatology, 2020 (04): 241-242-243-244-245 [2020-10-25].

4. Hua Chengge, Liu Zhiqing, Wang Qing, Yang Zheng, Xu Qinghong, Zhang Jing. From the view of prevention and control o f new coronavirus pneumonia epidemic situation, the management strategy of dental clinic in epidemic period is $[\mathrm{J}]$., Huaxi stomatology journal, 2020,38 (02): 117-121. R. Nicole, "Title of paper with only first word capitalized," J. Name Stand. Abbrev., in press.

5. Zhu Jun. Small oral cavity hidden 100 billion market [J]. Chinese brand, 2019 (12): 76-79. 